\title{
Glial Fibrillary Acidic Protein in the Cerebrospinal Fluid: A Possible Indicator of Prognosis in Full-Term Asphyxiated Newborn Infants?
}

\author{
MATS BLENNOW, HENRIK HAGBERG, AND LARS ROSENGREN \\ Institution of Woman and Child Health, Karolinska Hospital, Stockholm, Sweden [M.B.]; and Departments \\ of Obstetrics and Gynaecology [H.H.] and Anatomy and Cell Biology [H.H, L.R.], University of \\ Gothenburg, Gothenburg, Sweden
}

\section{ABSTRACT}

Glial fibrillary acidic protein (GFAP) is the structural protein of intermediate filaments in astroglia. GFAP has extensively been used as a marker of gliosis in neuropathology. It also appears in excessive amounts in the cerebrospinal fluid in various acute brain disorders. Hypoxic-ischemic encephalopathy after perinatal asphyxia is a condition in which levels of GFAP could be expected to be elevated if brain cell damage occurs. We examined levels of GFAP by a sensitive ELISA in the cerebrospinal fluid of full-term infants between 12 and $48 \mathrm{~h}$ after birth. Cerebrospinal fluid-GFAP increased 5-fold in infants after perinatal asphyxia compared with a reference group (675 versus 137 $\mathrm{ng} / \mathrm{L}, p<0.001)$. The levels of GFAP also increased gradually in accordance with the severity of the neurologic symptoms ranked as degree of hypoxic-ischemic encephalopathy. We con- clude that the cerebrospinal fluid levels of GFAP might be an important adjunct in the neonatal assessment of infants subject to perinatal asphyxia, and together with other neuronal or glial proteins, it might also help in defining temporal relationships in asphyxia. (Pediatr Res 37: 260-264, 1995)

Abbreviations

GFAP, glial fibrillary acidic protein

CSF, cerebrospinal fluid

MBP, myelin basic protein

CKBB, brain-specific creatine kinase

HIE, hypoxic-ischemic encephalopathy

CT, computed tomography
GFAP is the structural protein of the astroglial filaments (1). Using immunochemical techniques, it is frequently used as an astrocyte marker in brain pathology. In the CSF, GFAP is detectable in low concentrations under normal conditions (2, 3). Very high CSF levels of GFAP have been reported (3-5) after acute CNS injury, probably as a consequence of disintegration of astroglial cells. Moderately increased levels of GFAP in the CSF have also been found in chronic brain disorders such as Alzheimer's disease, multiinfarct dementia, and recently also in infantile autism $(2,3,6)$. In these disorders, gliosis is the probable cause of the observed increase. CSFGFAP levels increase rapidly within the first $48 \mathrm{~h}$ after acute ischemic injury (5). Thus, repetitive analysis of GFAP in the CSF might aid in dating insults with less clear-cut time se-

Received May 2, 1994; accepted October 3, 1994

Correspondence: Mats Blennow, M.D., Department of Pediatrics, Karolinska Hospital, S-171 76 Stockholm, Sweden.

Supported by grants from the Swedish Medical Research Council (Grants B94-12X09455 to H.H., K93-12P-10150 and B94-12X-09883 to L.R., and B94-19X-05234 to H. Lagercrantz), Linnéa and Josef Carlssons Foundation, the Samaritan Foundation, the Sunnerdahl's Foundation, The First of Mayflower Annual Campaign, The Edith Jacobson's Foundation, and the Jerring Foundation. quences than strokes. Excessive levels of GFAP have been found to correlate with infarct size and prognosis in strokes (3, 5).

Prediction of neurologic sequelae in full-term asphyxiated infants is traditionally based on clinical findings (7), neurophysiologic examinations (8-10), and brain imaging (11). In severely ill infants, the first two of these parameters are affected by medications and therapeutic interventions, such as antiepileptic pharmacotherapy, ventilator treatment, and muscle paralysis. This has led to an intense search for a valid biochemical method that could give accurate information on prognoses. However, no individual parameter has so far been shown to be of proven value (12), even if shifts in high energy compounds analyzed by means of magnetic resonance spectroscopy have been shown to correlate well with prognoses (13). Based on new insights in the pathophysiology of brain damage, we recently published data on levels of excitatory amino acids in the CSF (14) of asphyxiated infants showing significant increases of glutamate and aspartate compared with controls. Some attempts at finding brain-specific proteins in blood indicative of prognosis have also been previously re- 
ported $(15,16)$. This study is along another path, which is that of examining effects of hypoxic-ischemia on glial elements in CSF.

We wanted to investigate whether GFAP is measurable in the CSF of full-term newborns and, if so, whether hypoxicischemic brain damage in the full-term infant alters these values and correlates with other known indicators of prognosis.

\section{METHODS}

Samples were collected during the period between January 1990 and December 1992 at the neonatal intensive care unit at the Karolinska Hospital. The study was approved by the ethical committee of the hospital, and parental consent was obtained before inclusion in the study. The protocol included two study groups.

Asphyxia group. Full-term (gestational age 37-42 wk) newborn infants subjected to perinatal asphyxia based on fulfillment of the following criteria. 1) Intrapartum distress as indicated by the cardio-tochograph-pattern (late decelerations for $>1 \mathrm{~h}$ or severe abnormalities as absent variability or persistent bradycardia for $>30 \mathrm{~min}$ before birth), early passage of thick meconium, or scalp $\mathrm{pH}<7.2$ immediately before birth. 2) Need for neonatal resuscitation with positive pressure ventilation for $>3 \mathrm{~min}, 5$-min Apgar score $<6$, or umbilical arterial/ first postnatal $\mathrm{pH}<7.1$ and/or base excess $<-10$.

Reference group. Full-term neonates in which lumbar punctures were performed as part of the bacterial workup due to suspicion of systemic bacterial infection and without findings indicating CNS pathology (negative CSF culture, negative neurophysiology, and normal outcome).

The number of infants in each group, their gender, mean values for birth weight, 5-min Apgar score, and age at sampling are given in Table 1 . One infant in the asphyxia group was excluded due to a subarachnoidal hemorrhage with CSF containing blood macroscopically. One infant in the reference group was excluded when obstetric data from the referring hospital arrived including evidence of intrapartum asphyxia judged from fetal heart rate patterns and meconium-stained amniotic fluid.

Infants were monitored with a cardiorespirograph, transcutaneous oxygen pressure/pulsoxymetry, and an assistant nurse by the incubator continuously during treatment in the neonatal unit. In addition, the following diagnostic and scientific investigations were performed in the asphyxia group. All neonates were scored daily for the first week of life by the same examiner for signs of HIE according to Sarnat and Sarnat (17), and the severest degree was used for statistical calculations.

Table 1. Clinical data on the studied infants

\begin{tabular}{|c|c|c|c|c|c|}
\hline & $\begin{array}{c}\text { Gestational } \\
\text { Age (wk) }\end{array}$ & Birth wt (g) & $\begin{array}{c}\text { Sex } \\
(\mathrm{M} / \mathrm{F})\end{array}$ & $\begin{array}{l}\text { 5-Min } \\
\text { Apgar } \\
\text { Score } \\
\text { (points) }\end{array}$ & $\begin{array}{l}\text { Lumbar } \\
\text { puncture } \\
\text { age (h) }\end{array}$ \\
\hline $\begin{array}{l}\text { Asphyxia group } \\
\quad(n=21)\end{array}$ & $39.9 \pm 0.4$ & $3218 \pm 133$ & $12 / 9$ & $4.4 \pm 0.6$ & $31.0 \pm 4.8$ \\
\hline $\begin{array}{l}\text { Reference group } \\
\quad(n=10)\end{array}$ & $38.6 \pm 0.6$ & $3359 \pm 257$ & $5 / 5$ & $9.2 \pm 0.3$ & $37.5 \pm 10.5$ \\
\hline
\end{tabular}

Infants with no symptoms or with mild HIE were considered to have a good prognosis. Infants with moderate or severe HIE were considered to have a poor prognosis. Infants in the latter group were examined by CT scan of the brain (11) on d 3-5. EEG or amplitude integrated EEG (Cerebral Function Monitor, Lectromed UK Limited, England) (10) were done as soon as possible, and at $1 \mathrm{wk}$ of age. The asphyxiated infants were examined by a neuropediatrician at 9,18 , and 48 mo of age and classified as normal, suspect (nondisabling abnormalities in tone and reflexes), or abnormal (disabling abnormalities in tone and reflexes, seizures, or blindness). Infants in the suspect or abnormal categories were considered to have an abnormal outcome. Infants in the reference group were followed-up as indicated at discharge, and information was also collected from the responsible well-baby clinic.

CSF sampling. CSF was collected by spinal taps in the L3- 4 region between 12 and $48 \mathrm{~h}$ of age. After $1.5 \mathrm{~mL}$ of CSF necessary for clinical purposes had been tapped, the next 0.5 $\mathrm{mL}$ was collected and the sample was immediately frozen in a mixture of dry ice and $70 \%$ ethanol.

CSF analysis. The sandwich-type ELISA for determination of GFAP has been described in detail elsewhere (2). In short, CSF is incubated for $4 \mathrm{~h}$ in microplates coated with polyclonal hen $\alpha$-GFAP IgG. After washing, polyclonal rabbit $\alpha$-GFAP IgG is added and incubated overnight. Bound rabbit $\alpha$-GFAP is then detected by adding biotinylated goat $\alpha$-rabbit IgG and followed by incubation with peroxidase Vectastain $\mathrm{ABC}$ reagent (Vector Laboratories, Burlingame, CA). Ortophenylenediamine and $\mathrm{H}_{2} \mathrm{O}_{2}$ are used as enzyme substrates for the color reaction and the absorbance is measured at $490 \mathrm{~nm}$ using a computerized ELISA reader (Molecular Devices Corporation, Menlo Park, CA). Concentrations of GFAP are interpolated from standard curves ranging from 16 to $16000 \mathrm{ng} / \mathrm{L}$ using log-log transformation. Levels of hypoxanthine (18) in the CSF were analyzed using HPLC (19).

Data analysis. Levels of GFAP and hypoxanthine are given as medians and interquartile ranges. The Mann-Whitney $U$ test was used to test differences between the asphyxia group and the reference group, and between asphyxiated infants with good and poor prognosis as judged from the degree of encephalopathy. The Kruskal-Wallis test was used to test the differences between different degrees of encephalopathy. Spearman rank correlation was used to test correlations among different measured parameters. In the asphyxiated group sensitivity, specificity, and the predictive values of normal and abnormal results of GFAP, HIE, EEG, and CT scan were calculated.

\section{RESULTS}

In the asphyxia group $(n=21)$, four infants developed mild, 13 moderate, and two severe HIE. Two infants showed no abnormal neurologic symptoms after the initial resuscitation. Sixteen infants developed seizures between 2 and 48 h postnatally. No infants died.

The mean age at lumbar puncture was $31 \mathrm{~h}$ in the asphyxia group and $37 \mathrm{~h}$ in the reference group. Mean $( \pm \mathrm{SD})$ red blood cell counts were $4986 \pm 2638$ and $2853 \pm 2301$ (NS) in the asphyxia and reference group, respectively. The CSF protein 
concentration amounted to $1.52 \pm 0.18 \mathrm{~g} / \mathrm{L}$ in the asphyxiated infants and $1.37 \pm 0.20 \mathrm{~g} / \mathrm{L}$ in the reference infants (NS). No significant correlations were found between GFAP values and either red blood cell counts or protein contents.

GFAP concentration was 5 times higher (median $675 \mathrm{ng} / \mathrm{L}$; 407-944) in the CSF of asphyxiated infants than in the reference group (137 ng/L; 56-290; $p<0.001)$ (Fig. 1). Figure 1 also shows the levels of GFAP in the asphyxiated infants with a good prognosis, i.e. those without and with mild HIE compared with those with the worst prognosis (moderate and severe HIE) and to the reference group. A significant difference was found between the groups $(p<0.001$; Kruskal-Wallis test). GFAP levels were two times higher in moderate (747 $\mathrm{ng} / \mathrm{L} ; 656-984)$ and 5-fold higher in the two cases of severe HIE (1768 ng/L; 423-3125) than in those asphyxiated infants with normal neurologic examinations $(355 \mathrm{ng} / \mathrm{L} ; 264-485)$ or with mild HIE (401 ng/L; 204-509) $(p<0.01)$.

In five infants, CSF samples were obtained at more than one occasion. In four of these infants, GFAP levels increased during the first $24-48 \mathrm{~h}$ of life (Fig. 2).

Levels of hypoxanthine did not differ between the asphyxia group $(4.3 \mu \mathrm{mol} / \mathrm{L} ; 2.6-6.1)$ and the reference group $(4.0$ $\mu \mathrm{mol} / \mathrm{L} ; 3.4-5.9)$. There was no correlation between hypoxan-

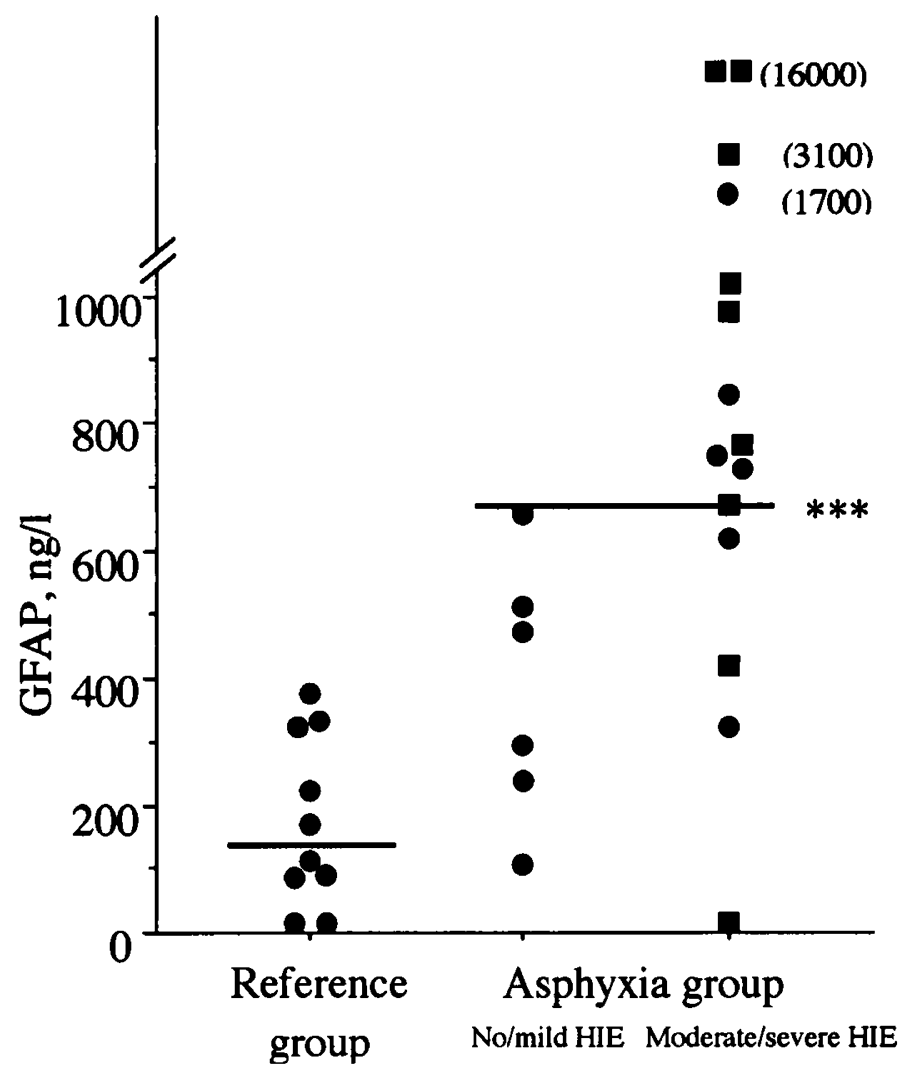

Figure 1. CSF concentrations of GFAP in the asphyxia $(n=21)$ and the reference $(n=10)$ groups. The asphyxia group is subdivided according to prognosis based on clinical examination $(\mathrm{No} / \mathrm{mild} \mathrm{HIE}=$ good, moderate/ severe $\mathrm{HIE}=$ adverse prognosis). Values are expressed as $\mathrm{ng} / \mathrm{L}$ and the horizontal bars indicate median values in the reference and asphyxia group, respectively. Outcome for the infants is indicated by the symbols: squares, adverse outcome; circles, normal outcome. The Mann-Whitney $U$ test was used to evaluate the difference between the reference and the asphyxia groups: ${ }^{* * *}, p<0.001$.

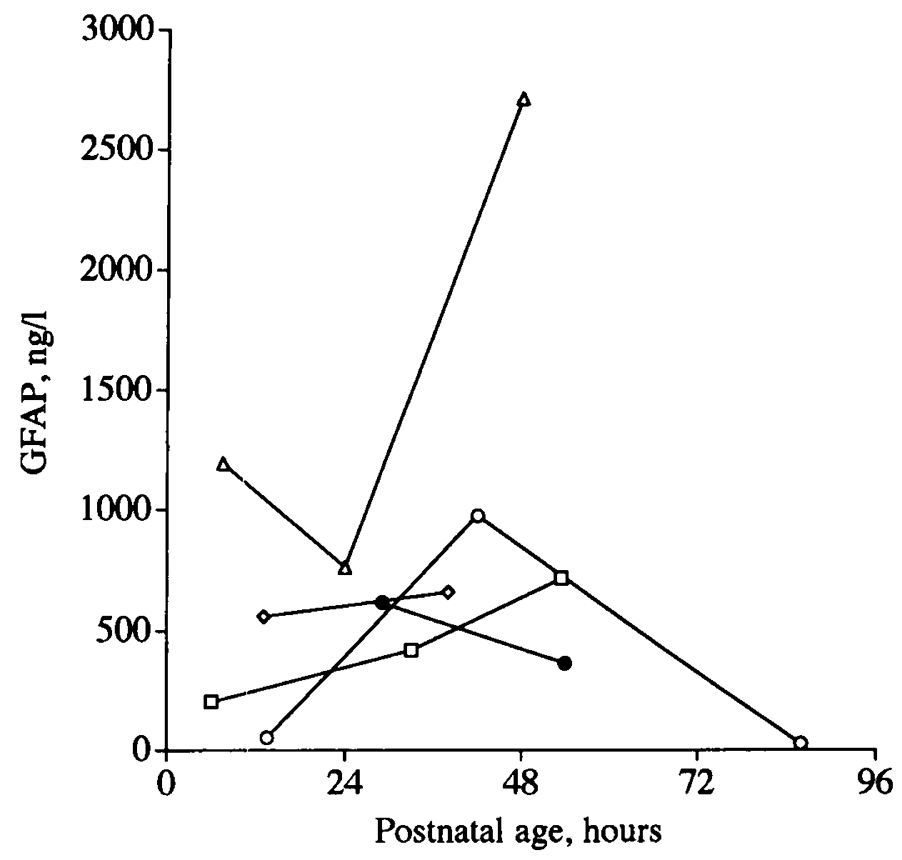

Figure 2. CSF concentrations of GFAP (ng/L) in five asphyxiated infants in which more than one sample was obtained.

thine and the degree of HIE or between the levels of hypoxanthine and GFAP.

Seven of nine infants with adverse outcomes at the latest examination (between 10 and $48 \mathrm{mo}$ ) had GFAP levels exceeding the highest value in the asphyxiated group with no or mild HIE (Fig. 1). However, four of the infants with very high GFAP levels have so far had normal neurodevelopmental examinations. In Table 2 values for sensitivity, specificity, and predictive values of normal and abnormal results for GFAP are given together with the corresponding values for HIE, EEG, and CT scan. The highest GFAP value among asphyxiated infants with no or mild HIE $(659 \mathrm{ng} / \mathrm{L})$ was chosen as the upper limit to predict a normal outcome.

\section{DISCUSSION}

The potential of brain-specific proteins as adjuncts in the clinical assessment in various cerebral diseases is interesting for many reasons. First, in the critically ill patient, they might aid in the differential diagnosis of whether the condition is due to a cerebral disease/injury or not. Second, depending on the cell type of origin, these proteins are thought to selectively reflect damage to neurons, glial cells, or myelin (20). Thus,

Table 2. Comparison of sensitivity, specificity, predictive values of abnormal/normal results for GFAP, HIE, EEG, and CT scan

\begin{tabular}{|c|c|c|c|c|c|}
\hline & $n$ & $\begin{array}{c}\text { Sensitivity } \\
(\%)\end{array}$ & $\begin{array}{c}\text { Specificity } \\
(\%)\end{array}$ & $\begin{array}{l}\text { Predictive value of } \\
\text { abnormal result } \\
\text { (\%) }\end{array}$ & $\begin{array}{l}\text { Predictive value of } \\
\text { normal result }(\%)\end{array}$ \\
\hline GFAP & 21 & 78 & 75 & 64 & 80 \\
\hline HIE & 21 & 100 & 50 & 60 & 100 \\
\hline EEG & 21 & 89 & 58 & 62 & 88 \\
\hline CT scan & 13 & 33 & 57 & 40 & 50 \\
\hline
\end{tabular}

A value above the highest value of CSF-GFAP in the group of asphyxiated infants with no or mild HIE was considered to predict an adverse outcome. 
acute bouts of demyelination have been shown to increase CSF levels of MBP (21), whereas patients suffering from diseases with proposed gliosis, such as Alzheimer's dementia (6) and infantile autism $(2,22)$, exhibit elevations of GFAP. Next, as many of these proteins show a nonspecific increase in reaction to acute cell damage $(5,23-25)$ but with different time patterns of release, concomitant analysis of several of them, as well as sequential analysis of the individual proteins, might prove efficacious in dating insults. Thus, GFAP and S-100 have been shown (5) to increase within the first 12-48 $\mathrm{h}$ after acute CNS damage, whereas MBP (24) after strokes in adults has a slower increase, and reaches peak values 4-5 d after the insult. Finally, brain-specific proteins may prove valuable, both in the selection for, and follow-up after, pharmacologic interventions aiming at cerebral protection.

The release of brain-specific proteins to the CSF have been investigated thoroughly during the last decades. After strokes in adults increases of $\operatorname{MBP}(24,25), \operatorname{CKBB}(25,26)$, neuronspecific enolase $(27,28), \mathrm{S}-100$, and $\operatorname{GFAP}(4,5,27,29,30)$ have been shown. In the study of brain-specific proteins, several investigators point to the necessity of age-matched controls $(3,31)$, as CSF values steadily increase with age. However, little is known about the concentrations of these proteins in blood and CSF of the healthy and the critically ill newborn infants. MBP in the CSF has been shown to be elevated in children with increased intracranial pressure, but not in children with seizures (32). These authors conclude that the prognostic value in measuring CSF-MBP in the individual patient is low. Glial protein markers in pediatric populations have recently been studied in neuropsychiatric patients $(2,22)$, where elevated levels of GFAP were found in children with infantile autism and basal ganglia disorders. In one earlier study, GFAP was measured in children with subacute sclerosing panencephalitis or severe brain degenerative disease due to metabolic storage or lysosomal diseases (6) and increased levels were found in some cases. CKBB in serum has been shown to increase within the first $4-15 \mathrm{~h}$ of life in infants after perinatal asphyxia $(15,33,34)$. However, the predictive value of CKBB was equal or inferior to that of clinical, neuroradiologic, or neurophysiologic examinations in one study. Another potential problem with CKBB is that, apart from the brain, it is also expressed in other tissues such as the placenta, the gastrointestinal tract, and the kidneys, organs that might be involved in the sequelae of perinatal asphyxia. In a recent study, neuron-specific enolase and MBP were shown to be increased in the CSF of asphyxiated newborn infants (35).

In our study, the CSF-GFAP concentrations of the asphyxiated infants were increased five times compared with the reference level. An even more pronounced increase was seen in infants with neonatal symptoms of moderate or severe HIE, i.e. the infants that have the poorest prognosis. The levels of GFAP found in our reference group were high when compared with normal values of children and young adults (2). This could be due to an increased leakage of GFAP from the astroglia to the CSF in the rapidly developing neonatal brain, perhaps enhanced by the inevitable stress and hypoxia imposed by normal birth. However, we used infants treated in the neonatal intensive care unit due to a suspicion of systemic infection as controls. Thus, it is possible that infants in the reference group all were neurologically stigmatized, albeit they all had normal neurologic examinations and negative blood and CSF cultures. This could mean that the levels of GFAP in our reference group differ from the general population of healthy infants.

The reason for the elevated levels of GFAP after asphyxia is not distinctly clear. The most likely mechanism is leakage of GFAP to the extracellular fluid after disruption of glial cellular membranes and glial cell death due to cerebral hypoxia. The gliotic reaction, beginning after $1-2 \mathrm{~d}$ in response to the injury, may contribute to, but can hardly explain, more than a part of the GFAP increase observed, at least in the severely affected cases. Furthermore, a rapid rise of GFAP synthesis has been shown in response to hypoxic damage that may relate to activation of glial cells with release of GFAP into the extracellular space and CSF (36).

In our small material of infants with more than one sample collected, we found a rapid GFAP increase in four of five cases during the first $24-48 \mathrm{~h}$ of life. The finding is interesting, suggesting a possible time-specific pattern similar to the transient increase of CSF-GFAP in adults after focal ischemia (5). If these findings are confirmed in additional asphyxiated infants, analyses of GFAP and other brain-specific proteins, with other time patterns of release, will be valuable tools in deciding temporal relationships of perinatal brain injury. GFAP may prove to be an acute-phase protein of the CNS, resembling in this manner lactate-dehydrogenase and creatine kinase in ischemic heart disease.

As our material is small and the follow-up period hitherto is limited, we hesitate to draw any conclusions on the predictive values of CSF-GFAP analysis, especially in relation to the other predictive methods. However, in this material the most sensitive method for prognosis was HIE grading during the first days of treatment. Unfortunately, HIE had a high rate of false-positive cases if adverse outcome was predicted by moderate or severe HIE (40\%). Antiepileptic medication might partly explain this. These circumstances further stress the need for a more objective marker. CT scans had very poor predictive capacity in the cases studied and EEG also had many falsepositive cases. Thus, we find the figures for CSF-GFAP promising in relation to prognosis. Hypoxanthine in the CSF was analyzed, because it has been proposed as a golden marker of hypoxia (37). No correlation with either severity of symptoms or with GFAP was seen. One explanation might be that our sampling was delayed until a mean age of $31 \mathrm{~h}$, by which time an accumulation might have disappeared, either by further catabolism to uric acid, or regeneration to inosine and adenosine.

We conclude that it is possible to measure GFAP in the CSF of newborn infants. After perinatal asphyxia, GFAP is released to the CSF in excessive amounts, and the levels correlate with our recent tools for the prediction of future handicaps. More studies are required to determine the role of CSF-GFAP analysis in determining time sequences in perinatal asphyxia.

\section{REFERENCES}

1. Rueger D, Huston J, Dahl D, Bignami A 1979 Formation of $100 \AA$ filaments from purified glial fibrillary acidic protein in vitro. J Mol Biol 135:53-68 
2. Rosengren LE, Ahlsen G, Belfrage M, Gillberg C, Haglid KG, Hamberger A 1992 A sensitive ELISA for glial fibrillary acidic protein: application in CSF of children. $J$ Neurosci Methods 44:113-119

3. Rosengren LE, Wikkelsø C, Hagberg L 1994 A sensitive ELISA for glial fibrillary acidic protein: application in CSF of adults. J Neurosci Methods 51:197-204

4. Hayakawa R, Ushio Y, Mori T, Arita N, Yoshimine T, Maeda Y, Shimizu K, Mygoa A 1979 Levels in stroke patients of an astrocyte-specific cerebroprotein. Stroke 10:685-689

5. Aurell A, Rosengren LE, Karlsson B, Olsson JE, Zbornikova V, Haglid KG 1991 Determination of S-100 and glial fibrillary acidic protein concentrations in cerebrospinal fluid after brain infarction. Stroke 22:1254-1258

6. Crols R, Saerens J, Noppe M, Lowenthal A 1986 Increased GFAP levels in CSF as a marker of organicity in patients with Alzheimer's disease and other types of irreversible chronic brain syndromes. J Neurol 233:157-160

7. Levene M, Grindulis H, Sands C, Moore JR 1986 Comparison of two methods of predicting outcome in perinatal asphyxia. Lancet 1:67-71

8. Watanabe K, Miyazaki K, Hakamada S 1980 Behavioural state cycles, background EEGs and prognosis of newborns with perinatal hypoxia. Electroencephalogr Clin Neurophysiol 49:618-625

9. Holmes G, Rowe J, Hafford J, Schmidt R, Testa M, Zimmerman A 1982 Prognostic value of the encephalogram in neonatal asphyxia. Electroencephalogr Clin Neurophysiol 53:60-72

10. Thornberg E, Ekström-Jodal B 1994 Cerebral function monitoring: a method of predicting outcome in term neonates after severe perinatal asphyxia. Acta Paediatr 83:596-601

11. Fitzhardinge P, Flodmark O 1981 The prognostic value of computed tomography as an adjunct to assessment of the term infant with postasphyxial encephalopathy. J Pediatr 99:777-781

12. Anonymous 1988 Biochemical assessment of birth asphyxia. Lancet 1:548-549

13. Azzopardi D, Wyatt JS, Cady EB, Delpy DT, Baudin J, Stewart AL, Hope PL, Hamilton PA, Reynolds EOR 1989 Prognosis of newborn infants with hypoxicischemic brain injury assessed by phosphorus magnetic resonance spectroscopy. Pediatr Res 25:445-451

14. Hagberg H, Thornberg E, Blennow M, Kjellmer I, Lagercrantz $\mathbf{H}$, Thiringer K, Hamberger A, Sandberg M 1993 Excitatory amino acids in the cerebrospinal fluid of asphyxiated infants: relationship to hypoxic-ischemic encephalopathy. Acta Paediatr 82:925-929

15. Fernandez F, Verdu A, Quero J, Perez-Higueras A 1987 Serum CPK-BB isoenzyme in the assessment of brain damage in asphyctic term infants. Acta Paediatr Scand 76:914-918

16. Becker M, Menzel K 1980 Brain-typical creatine kinase in the serum of newborn infants with perinatal brain damage. Acta Paediatr Scand 67:177-180

17. Sarnat H, Sarnat M 1976 Neonatal encephalopathy following fetal distress. Arch Neurol 33:696-705

18. Meberg A, Saugstad O 1978 Hypoxanthine in cerebrospinal fluid in children. Scand $\mathrm{J}$ Clin Lab Invest 38:437-440

19. Simmonds RJ, Harkness RA 1981 High-performance liquid chromatographic methods for base and nucleoside analysis in extracellular fluids and cells. J Chromatogr 226:369-381

20. Massaro AR, Michetti F, Laudisio A, Bergonzi P 1985 Myelin basic protein and S-100 antigen in cerebrospinal fluid of patients with multiple sclerosis in the acute phase. Ital J Neurol Sci 6:53-56
21. Noppe M, Crols R, Andries D, Lowenthal A 1986 Determination in human cerebrospinal fluid of glial fibrillary acidic protein, S-100 and myelin basic protein as indices of non-specific or specific central nervous tissue pathology. Clin Chim Acta 155:143150

22. Ahlsen G, Rosengren L, Belfrage M, Palm A, Haglid K, Hamberger A, Gillberg C 1993 Glial fib:illary acidic protein in the cerebrospinal fluid of children with autism and other neuropsychiatric disorders. Biol Psychiatry 33:734-743

23. Kruse A, Cesarini KG, Bach FW, Persson L 1991 Increases of neuron-specific enolase, S-100 protein, creatine kinase and creatine kinase BB isoenzyme in CSF following intraventricular catheter implantation. Acta Neurochir 110:106-109

24. Strand T, Alling C, Karlsson B, Karlsson I, Winblad B 1984 Brain and plasma proteins in spinal fluid as markers for brain damage and severity of stroke. Stroke 15:138-144

25. Matias-Guiu J, Martinez VJ, Ruibal A, Colomer R, Boada M, Codina A 1986 Myelin basic protein and creatine kinase BB isoenzyme as CSF markers of intracranial tumors and stroke. Acta Neurol Scand 73:461-465

26. Pfeiffer F, Homburger H, Yanagihara T 1983 Creatin kinase BB isoenzyme in cerebral spinal fluid in neurological disease. Measurement by radioimmunoassay. Arch Neurol 4():169-172

27. Mokuno K, Kato K, Kawai K, Matsuoka Y, Yanagi T, Sobue I 1983 Neuron- specific enolase and S-100 protein in CSF of patients with various neurological diseases. J Neurol Sci 60:443-451

28. Scarna H, Steinberg R, Delafosse B, Debilly G, Mandrand B, Keller A, Pujol J 1983 Neuron-specific enolase in biological fluids: a marker of neuronal lesion. In: Peeters H (ed) Protides of the Biological Fluids, Vol 30. Pergamon Press, Oxford, UK, pp 55-60

29. Kato K, Nakajina T, Ishiguto $Y$, Matsutani T 1982 Sensitive enzyme immunoassay S-100 protein: cletermination in human cerebrospinal fluid. Biomed Res 3:24-28

30. Persson L, Hårdemark H-G, Gustavsson J, Rundström G, Mendel-Hartvig I, Essche T, Påhlman S 1987 S-100 protein and neuron specific enolase in cerebrospinal fluid and serum: markers of cell damage in human central nervous system. Stroke 18:911-918

31. van Engelen B, Lamers KJ, Gabreels FJ, Wevers RA, van GW, Borm GF 1992 Age-related changes of neuron-specific enolase, S-100 protein, and myelin basic protein concentrations in cerebrospinal fluid. Clin Chem 38:813-816

32. Levin SD, Hoyle NR, Brown JK, Thomas DG 1985 Cerebrospinal fluid myelin basic protein immunoreactivity as an indicator of brain damage in children. Dev Med Child Neurol 27:807-813

33. Walsh P, Jedeikin R, Ellis G, Path MCP, Primhak R, Makela SK 1982 Assessment of neurologic outcome in asphyxiated term infants by use of serial CK-BB isoenzyme measurement. J Pediatr 101:988-992

34. Cuestas RA 1980 Creatine kinase isoenzymes in high-risk infants. Pediatr Res $14: 935-938$

35. Garcia AA, Cabanas F, Pellicer A, Hernanz A, Stiris TA, Quero J 1994 Neuronspecific enolase and myelin basic protein: relationship of cerebrospinal fluid concentrations to the rieurologic condition of asphyxiated full-term infants. Pediatrics 93:234-240

36. Rischke R, Krieglstein J 1991 Postischemic neuronal damage causes astroglial activation and increase in local cerebral glucose utilization of rat hippocampus. $J$ Cereb Blood Flow Metab 11:106-113

37. Pietz J, Guttenberg N, Gluck L 1988 Hypoxanthine: a marker for asphyxia. Obstet Gynecol 72:762-766 